\title{
¿Should I Stay or Should I Go? South Indian Artisanal Fishers' Precarious Livelihoods and Their Engagement with Categorical Ocean Forecasts
}

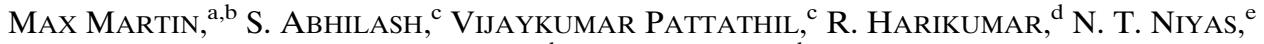 \\ T. M. BALAKRISHNAN NAIR, ${ }^{\mathrm{d}}$ YATIN GROVER, ${ }^{\mathrm{d}}$ AND FILIPPO OSElla ${ }^{\mathrm{a}}$ \\ ${ }^{a}$ Department of Anthropology, University of Sussex, Brighton, United Kingdom \\ ${ }^{\mathrm{b}}$ Department of Geography, University of Sussex, Brighton, United Kingdom \\ ${ }^{c}$ Department of Atmospheric Sciences, Cochin University of Science and Technology, Cochin, India \\ ${ }^{\mathrm{d}}$ Indian National Centre for Ocean Information Services, Ministry of Earth Sciences, Pragathi Nagar, India \\ ${ }^{\mathrm{e}}$ India Meteorological Department, Ministry of Earth Sciences, New Delhi, India
}

(Manuscript received 13 April 2020, in final form 17 September 2021)

\begin{abstract}
Ocean State Forecasts contribute to safe and sustainable fishing in India, but their usage among artisanal fishers is often limited. Our research in Thiruvananthapuram district in the southern Indian state of Kerala tested forecast quality and value and how fishers engage with forecasts. In two fishing villages, we verified forecast accuracy, skill, and reliability by comparing forecasts with observations during the 2018 monsoon season (June-September; $n=122$ ). We assessed forecast value by analyzing fishers' perceptions of weather and risks and the way they used forecasts based on 8 focus group discussions, 20 interviews, conversations, and logs of 10 fishing boats. We find that while forecasts are mostly accurate, inadequate forecasting of unusual events (e.g., wind $\left.>45 \mathrm{~km} \mathrm{~h}^{-1}\right)$ and frequent fishing restrictions $(n=32)$ undermine their value. Fishers seek more localized and detailed forecasts, but they do not always use them. Weather forecasts are just one of the tools artisanal fishers deploy, used not simply to decide as to whether to go to sea but also to manage potential risks, allowing them to prepare for fishing under hazardous conditions. Their decisions are also based on the availability of fish and their economic needs. From our findings, we suggest that political, economic, and social marginality of south Indian fishers influences their perceptions and responses to weather-related risks. Therefore, improving forecast usage requires not only better forecast skill and wide dissemination of tailor-made weather information, but also better appreciation of risk cultures and the livelihood imperatives of artisanal fishing communities.
\end{abstract}

KEYWORDS: Asia; Climate change; Communications/decision making; Forecasting; Indian Ocean; Monsoons; Social Science; Waves, oceanic

\section{Introduction}

Marine weather forecasts contribute to safety at sea by providing vital information and warnings (WMO 2018; Finnis et al. 2019). However, research suggests that people engaged in weather-dependent activities-such as fishers-often use forecasts selectively, or altogether ignore them (Daipha 2012, 2015a,b; Attwood 2018), revealing an apparent gap between the production and use of weather knowledge (Lemos et al. 2012; National Research Council 2009, 2010). This gap has been attributed both to scientists' failure to effectively communicate forecasts (Lemos et al. 2014; Hov et al. 2017), and users' lack of appreciation of the contingent nature of forecasts (Attwood 2018).

Based on research in two coastal villages of Thiruvananthapuram district in Kerala (India), in this article we discuss factors that influence the use of forecasts by artisanal fishers. We engage with two related bodies of research that address shortcomings in forecast communication and usage. The first focuses on the circulation of weather information and warnings between scientists and users, and suggests that user-friendly packaging of scientific data, effective

¿ Denotes content that is immediately available upon publication as open access.

Corresponding author: Max Martin, max.martin@sussex.ac.uk dialogue among stakeholders, and mediation through boundary organizations would lead to better, if not optimal, compliance to forecasts (see Lemos et al. 2012, 2014; Hov et al. 2017). The second addresses the cognitive and practical means through which forecast users understand and engage with weather. Here, we find that end users do not necessarily take forecasts at face value but deploy a process of creative assemblage of different sources, perceptions, and information to accommodate forecasts or advisories to their plans and routines (Daipha 2012, 2015a,b). By bringing forecast users "at the center" (Bulengela et al. 2020, p. 562), these two bodies of research suggest that the communication and usage of forecasts can be made more effective either by involving users in a process of "coproduction" of weather knowledge (see Roncoli et al. 2009; Lemos et al. 2012, 2014; Kirchhoff et al. 2015; Hov et al. 2017), or by tailoring forecasts toward users' risk-reduction and decision-making strategies (Daipha 2015b; Saldanha et al. 2020; see also Montz 2009; Montz et al. 2017).

We acknowledge that several factors can impede effective use of forecasts. The gap between usable and useful weather information (Lemos et al. 2012) is caused by what has been termed as a "strong disconnect" between information needed and provided (Rasmussen and Mertz 2014, p. 482). In this regard, the "deficit model" proposes that the scale of forecasts in time and space, timing of the bulletins, different interpretations and information needs of user groups, and the lack of appreciation of underlying poverty and disparities among the users pose serious challenges in forecast usage (Vogel and O'Brien 2006; Vogel 
et al. 2019). For instance, Patt and Gwata (2002) identify six impediments to effective forecast use-credibility, legitimacy in terms of how forecasts align with useful local knowledge, scale, cognition (denoting whether forecasts are clear and easily understood), procedural factors such as timing and routing of information, and choices offered for decision-making. In short, it may be argued that the usefulness of forecasts is dependent not only on their accuracy but also their alignment with the recipients' information needs and livelihood adaptation strategies in a changing climate (National Research Council 1999, 2009).

While people's information needs differ, socioeconomic variables and social networks influence or even constrain the use of forecasts, as studies on the coast of Peru in the context of El Niño events show (Broad et al. 2002; Orlove et al. 2004). However, researchers often fail to appreciate how interacting socioeconomic and cultural factors shape the way forecasts are used (Roncoli et al. 2009). Farmers in West Africa, for instance, consider several material and nonmaterial factors, while sociopolitical tensions-over administrative boundaries, land rights, and resources-and local power dynamics restrict their access to information and limit response options (Roncoli et al. 2009). The challenge here is to resolve the contrasting ways in which forecasters and forecast users look at weather and the world in general. Addressing this challenge requires a close look at "lived lives and the specificities of human experience" (Jasanoff 2010, p. 238).

On a broader plane, a substantial body of research has underscored the ways in which conditions of environmental and socioeconomic marginality can combine to increase people's vulnerabilities, making daily lives increasingly risk prone (Cannon 2006; Cutter et al. 2008). ${ }^{1}$ These studies also demonstrate that people experiencing the recurrent and cumulative effects of multiple forms of marginality develop and deploy contingent, context-specific, and culturally appropriate practices to contain or manage risk, lending degrees of resilience to their lives (Hewitt 1997, 2013a; Blaikie et al. 2004; Montz et al. 2017). In sum, attitudes and responses to (environmental) risks are inevitably enmeshed in "inescapable social constraints, expectations, responsibilities, and happenings" that inform everyday life (Hewitt 2013a, p. 13; see also Blaikie et al. 2004; Hewitt 2013b; Birkmann et al. 2012; Montz et al. 2017). We do not make a naïve call for appreciation of the sociocultural embeddedness of risk (Douglas and Wildavsky 1982). Rather, what is suggested here is that the process of turning (potential) hazards into measurable, and thus containable or manageable risks - whether via the deployment of specific technologies and bureaucratic arrangements (Samimian-Darash and Rabinow 2015; Latour 2005), or the evaluation of scientific knowledge through the lenses of users' experience and practices-is inevitably social and inchoate, and thereby open to multiple interpretations and contestations (see Power 2008; cf. Beck 1992, 1996; Giddens 1999; Szerszynski et al. 1996; Szerszynski 1999).

\footnotetext{
${ }^{1}$ These vulnerabilities can be exacerbated by prevailing planning, development, and governance practices (Pelling 2003, 2010; Bankoff et al. 2004).
}

Our study builds on this body of knowledge but shifts focus to a unique geographical area and time frame by studying artisanal fishers of South Asia, and their need for daily marine weather forecasts at a micro level. Our study suggests that there are inherent tensions in the ways that fishers and forecasters understand and respond to weather-related risk and uncertainty. Fishers might take their chances in the face of probable adverse weather conditions. They do this by weighing the dangers foreshadowed in forecasts and in advisories against their own experience, observations and, more importantly, their economic needs.

Extending these insights toward academic debates concerning forecast communication and usage, we suggest that the (spatial, political, economic, and social) marginality of south Indian fishers (Kurien 1985; Ouso 2014) have a direct bearing on their evaluation of and response to weather forecasts and advisories. We will argue, then, that the apparent shortcomings in the relation between forecast communication and usage among artisanal fishers in coastal south India (and beyond) cannot be assuaged simply by means of promoting the (co)production of tailor-made or culturally appropriate forecasts (Lemos et al. 2012; Kirchhoff et al. 2015). Rather, forecasts need to entail an evaluation of the quality and usefulness in relation to- thereby addressing and responding to- the conditions of marginality that inform artisanal fishers' own understandings, experiences, and management of the risks entailed in fishing under hazardous weather conditions. Such a move, we argue, is crucial in order to increase fishers' resilience in the face of climate change marked by abrupt changes, extremes, and uncertainties in weather patterns (Hov et al. 2017; IPCC 2012, 2019).

To support our argument, we unpack two common responses we received during fieldwork - and reported in many studies of forecast communication-to answer our questions around artisanal fishers' apparent lack of commitment to responding in a timely and consistent fashion to weather warnings. Artisanal fishers routinely claimed that weather forecasts were imprecise-or altogether wrong-leading to too many unwarranted restrictions on fishing, and therefore could not be taken at face value. For their part, forecasters attributed fishers' apparently erratic response to forecasts and advisories as caused by fishers' ignorance of scientific facts, cavalier attitude to safety at sea, and to a more general "unruly disposition."

After the background that follows, we assess the quality of marine weather forecasts and the relevance of the advisories received by artisanal fishers, before moving on to consider the extent to which these forecasts and advisories play a role in fishers' decisions concerning going to sea during the hazardous-and yet fish-rich-monsoon season. To assess the quality of forecasts and simultaneously consider the social context in which forecasts might be utilized, we necessarily employ a multidisciplinary and mixed methods approach. We combine methods and analytical insights from different disciplines-namely, meteorology, physical geography, sociology, and social anthropology - to investigate the production, communication, and utilization of weather forecasts from a novel, context-sensitive perspective. 


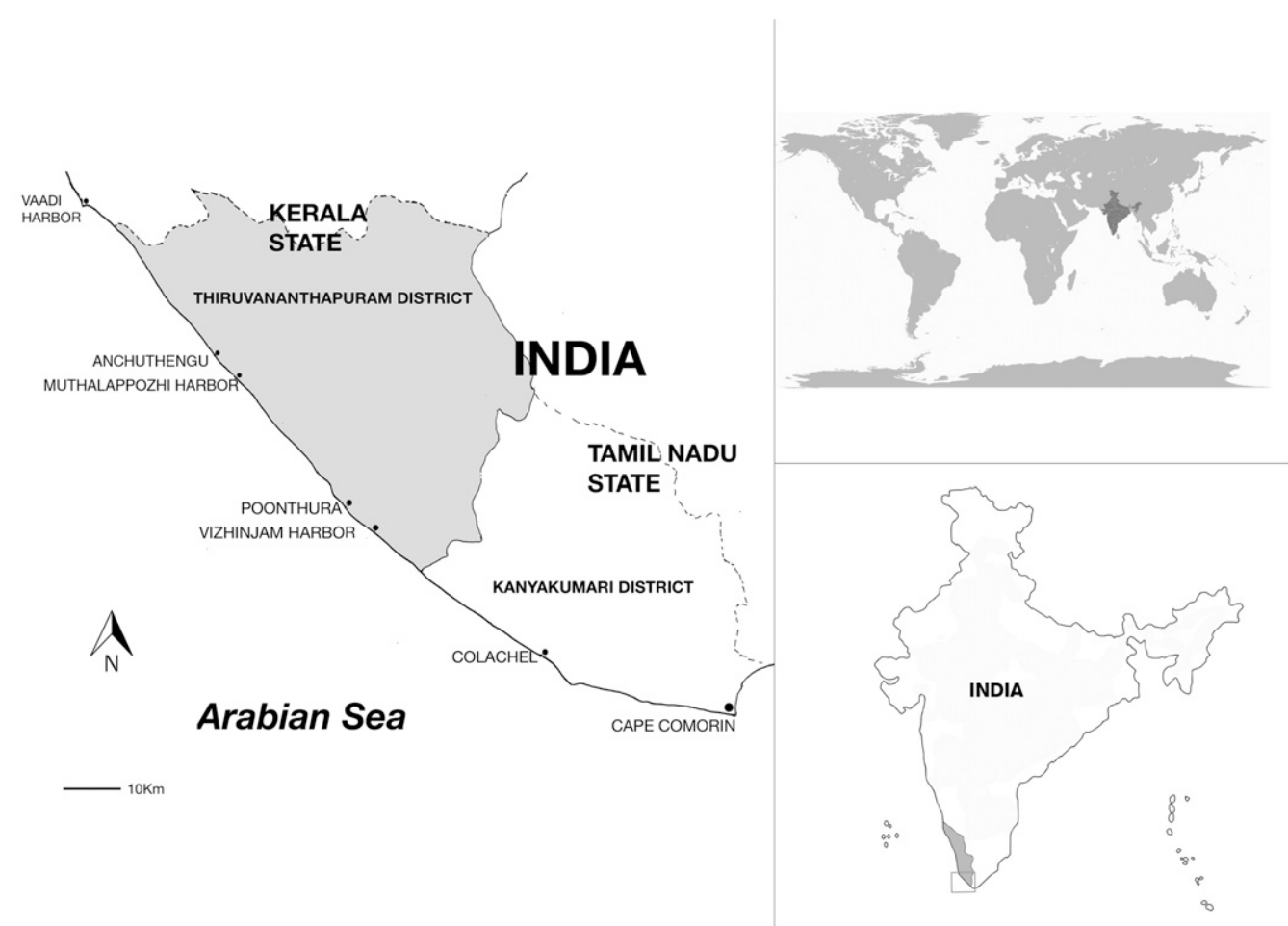

FIG. 1. Field-study sites.

\section{Background and context}

\section{a. Two coastal villages: Anchuthengu and Poonthura}

The study is located in a densely populated coastal region of Kerala. The state's $590-\mathrm{km}$ coastline is home to about one million people belonging to various marine fishing communities-differentiated by caste status as well as religious affiliation as Christian, Muslim, or $\mathrm{Hindu}^{2}$ - with around 180000 fishermen and their families living across 222 villages (Government of Kerala 2015). Comprising about 50000 active seagoing fishermen in 42 fishing villages, the coast of Thiruvananthapuram district in southern Kerala is characterized by artisanal fishing. Unlike neighboring areas, it has hardly any trawlers and little or no large-scale fishing. Our study area consists of fishers operating small motorized boats [of up to $34 \mathrm{ft}(\sim 10 \mathrm{~m})$ in length] — that are the most common fishing vessels here-alongside motorized fiberglass canoes and nonmotorized catamaran rafts $^{3}$ (South Indian Federation of Fishermen Societies 2017; Kurien 1996).

Research was conducted in two villages of Thiruvananthapuram district, covering the premonsooon and monsoon seasons

\footnotetext{
${ }^{2}$ By and large, Christian fishers are concentrated in the south of the state, whereas their Muslim counterparts are found mostly in north Kerala. Hindu fishers are located mostly in central and north Kerala.

${ }^{3}$ Images of motorized small boats, canoes, and catamaran rafts can be seen online (https://www.sahapedia.org/small-scalefisheries-of-major-fishing-villages-thiruvananthapuram-coast).
}

(Fig. 1). The two villages-Anchuthengu (formerly known as Anjengo) and Poonthura-were selected based on their similarities in social profiles and fishing methods but differences in exposure to the speed of the monsoon wind. Fishers of Poonthura, located $33 \mathrm{~km}$ south of Anchuthengu, often fish from the coastal waters farther south, exposed to the strong winds that come around Cape Comorin-the southernmost point of the Indian peninsula. Poonthura has 1290 artisanal fishing families, with over 1500 fishermen plying 361 boats with outboard engines and 44 nonmotorized craft. Anchuthengu has 2022 fisher families, 2006 of them artisanal, with 2340 active fishermen with 245 boats with outboard motors, and 33 nonmotorized vessels (Central Marine Fisheries Research Institute 2010).

The majority of fishers in Anchuthengu and Poonthura-as across the wider Thiruvananthapuram district and the adjoining Kanyakumari district of Tamil Nadu State-belong to the Mukkuvar community ${ }^{4}$ (Ram 1991; Subramanian 2009). They are Latin Catholics, state classified as an Other Backward Community (OBC) on the basis of their historical socioeconomic marginality. Apart from fostering grassroot community organization and trade unions, the Catholic Church plays an important role as an intermediary between fishers and state bureaucracy (Kurien 1985; Sundar 2012; Subramanian 2009). While their influence on the social lives of the fishers is indeed

\footnotetext{
${ }^{4}$ In these districts, there are a number of pockets of Hindu and Muslim fishing communities who, regardless of their historical roots, might or might not recognize themselves, or be recognized by others, as Mukkuvars (see Alex 2018; Punathil 2018).
} 
complex and open to contestations (see, e.g., Subramanian 2009; Ashni and Santhosh 2019), local churches and parish councils play a key role in regulating fishing-related matters-from the marketing of fish, to restricting fishing in line with government advisories - enforced at times with fines to those who contravene local arrangements. Although there is a degree of socioeconomic differentiation within our study areas-mostly due to the remittances of those who, over the years, have migrated to the gulf countries of west Asia-over $90 \%$ of families rely primarily on fishing (men) and selling fish (women) for their livelihood, or combine the latter with other sources of income such as driving three-wheelers and running small shops (Devika 2017).

On the southwestern coast, fish is particularly abundant during the monsoon season. At the same time the Arabian Sea is exposed to strong winds during the southwest monsoon season (June-September). ${ }^{5}$ Occasional long-period swells triggered by distant storms cause destructive high shore waves (Geetanath 2018; Osella et al. 2019). When the winds gain strength from May, frequent accidents occur even as the boats cross large waves close to the shore (South Indian Federation of Fishermen Societies 2017). In 2012, maritime agencies rescued 3046 fishermen in 454 operations off the shores of Kerala, but another 44 fishers lost their lives, and 11 went missing. During 2011-16, 643 accidents involving fishing boats were recorded in three coastal districts in south India, and $75 \%$ of these accidents involved small motorized boats (South Indian Federation of Fishermen Societies 2017). Recent studies have recorded a growing trend of frequent extreme weather events, such as intense storms over the Arabian Sea (Murakami et al. 2017; Central Marine Fisheries Research Institute 2020), including the devastating Cyclone Ockhi in 2017. At least 102 fishers from Kerala and neighboring Tamil Nadu State died as the result of Ockhi, and 263 fishers who went missing at sea were eventually declared dead. Coastal livelihoods were disrupted with the loss of 4591 fishing boats (Rijiju 2018).

\section{b. Precarious livelihoods and social marginality}

In south India as much as elsewhere in the global south weather-related accidents at sea occur in the dual context of the precarity of artisanal fishing and the socioeconomic marginality of fishing communities (South Indian Federation of Fishermen Societies 2017; Attwood 2018). Despite the apparent success of the well-known "Kerala model of development" (see Franke and Chasin 1994; Isaac and Franke 2000; Ramachandran 1997; Oommen 2007), which, in combination with the influx of migrants' remittances from west Asia, has led the state to achieve quality of life indicators comparable to those of so-called developed nations, the socioeconomic conditions of Kerala fishing communities have remained substantially lower than those of high-status communities in the state. Indeed, not only do fishers live in an extremely crowded environment, subject to destructive effects of coastal erosio$\mathrm{n}$-often residing in poor housing lacking proper sanitation and access to potable water-but fishers rank well below state

\footnotetext{
${ }^{5}$ See Pai and Rajeevan (2009) for details of the monsoon onset process and atmospheric phenomena.
}

average with reference to access to health services and education, ownership of land, and income (Kurien 1995; Government of Kerala 2015; Sathiadhas 2006; Shyam et al. 2014; Devika 2017). Regardless of state interventions, more than $50 \%$ of fishers' households are deemed to be below the poverty line-as opposed to a state average of 11\% (Ganga 2019)—and, more generally, they suffer high levels of indebtedness (Shyam et al. 2014). Moreover, while the costs of fishing-from fishing gear and engines, to petrol-has been increasing at a steady pace (Central Marine Fisheries Research Institute 2020), in recent years Kerala marine fish catch has declined, with reduction in species-sardines, for instance-which are the mainstay of artisanal fishers (Sathiadhas 2006; State Planning Board 2017; Central Marine Fisheries Research Institute 2015, 2020). Taken together, this has had the net effect of reducing fishers' household income (Shyam et al. 2014). While artisanal fishing communities emerge as the outliers of the "Kerala model of development" (Kurien 1995; see also Subramanian 2009), post-1991 economic liberalization has magnified even further the precariousness of fishers' livelihoods (Devika 2017; see also Ouso 2014; Subrahmanian and Prasad 2008).

The economic marginality of artisanal fishers is compounded by their (historical) low social status in Kerala's caste hierarchy (Ram 1991; Devika 2017; Kurien 2004; Subramanian 2009). While up to the early twentieth century fishers were the object of caste-based discrimination based on notions of ritual pollution, the same low status has come to be attributed since modernity as much to their relative poverty, as to their lack of "culture" and poor education, their intense and extrovert sociality, and their fiery responses to any encroachment on their autonomy (Osella and Osella 2000). Indeed, mainstream inland communities, popular press, police, and even state bureaucracy often stereotype coastal communities as beyond the rules of law and civility, while fishers are deemed to be volatile-if not altogether violent and dangerous (see, e.g., Punathil 2018; Aswathy and Kalpana 2019). Moreover, regardless of their sixteenth-century conversion from low-caste Hindus into Christianity, fishers continue to be discriminated against within the Catholic Church (Subramanian 2009).

Since the 1980s, artisanal fishers have come together under grassroot organizations and trade unions to oppose the introduction of trawling and large-scale mechanized fishing (see, e.g., Kurien and Achari 1988; Meynen 1989; Kurien 1991; Dietrich and Nayak 2002) and to resist government interventions regarded as deleterious to their fishing activities and livelihood (see, e.g., Ashni and Santhosh 2019). Combined with the weight of negative stereotyping and discriminations, the outcome of artisanal fishers' militant — at times violent—protests has been such that, while they are the object of state-led developmental interventions directed to "uplift" their socioeconomic conditions (see, e.g., Kurien and Paul 2001; Kurien 2004), they are simultaneously the object of strongarm policing from the state (Punathil 2018; Seethi 1995). Artisanal fishers' political mobilization in south Kerala-against the introduction of mechanized trawler fishing in the 1980s, and currently in opposition to the construction of a new container port at the site of one of Kerala State's main fishing harbors (Kurien and Achari 1988; Ashni and Santhosh 2019) — might have lent them collective voice and bargaining powers, but their marginal status appears unchanged. 
Fish catch is seasonal and perishable. Unlike the mechanized sector, artisanal fishers have no access to facilities to freeze, store, and transport fish and therefore sell the day's catch locally. The bulk of fishing income goes toward covering daily household expenses, acquiring or servicing fishing gear, and repaying debts. This means that without regular and successful fishing, income becomes uncertain or reduced, leading to increased indebtedness-often with high-interest informal loan providers-which then amplifies the precariousness of artisanal fishers' livelihood (Campling et al. 2012; Shyam et al. 2014; Devika 2017). State government's compensation for fishing days lost to adverse weather (and related restrictions) are insufficient to make up for the loss of income; our interviews show that artisanal fishers feel a substantial pressure to fish as often as they can. Recent studies have demonstrated that artisanal fishers are drawn to fishing into deeper waters farther away from the shore-and on longer forays-even under inclement weather conditions or in disregard of advisories (South Indian Federation of Fishermen Societies 2017). In summary, wider conditions of socioeconomic marginality combine with the unpredictability of fishing to predispose artisanal fishers toward prioritizing income over safety. As such, fishing remains one of the most precarious and dangerous occupations in south India (Kurien 2004; Devika 2017; Hapke and Ayyankeril 2018; see also Attwood 2018).

\section{Method}

We adopt an interdisciplinary approach for this research and use mixed quantitative and qualitative methods to test forecast quality and value (WMO 2000). Forecast quality denotes the degree to which forecasts correspond to actual weather conditions at sea, and value refers to the degree to which forecasts might inform users' decisions (Murphy 1993). Two methods broadly assess forecast quality and value: verification and user-based assessment. Verification of forecast quality involves testing (by statistical means) forecast accuracy, skill, and reliability (WMO 2000). Accuracy denotes how correctly weather phenomena are detected and forecast. Skill is measured against a benchmark forecast (typically climatology, chance, or persistence of weather phenomena) showing how forecasts become relevant and meaningful for users. Reliability denotes the extent to which forecast matches actual weather events, without bias. User-based qualitative assessment tests whether forecasts meet user requirements, and their overall effectiveness and credibility ${ }^{6}$ (WMO 2000). In user-based assessment, we focus on how forecasts meet the decision-making needs of fishers, especially in rough weather, and analysis takes into account the socioeconomic contexts in which artisanal fishers operate.

\section{a. Quantitative data}

We use quantitative methods to address the first research question: forecast quality. Forecast verification is a widely accepted method for assessment of accuracy, skill, and reliability of forecasts from a technical point of view (WMO

\footnotetext{
${ }^{6}$ This study includes only categorical forecasts and advisories relevant to marine fishing and not probabilistic forecasts.
}

TABLE 1. Forecast and observed wind contingency table. If both forecast and observed are yes, the event is classified as a hit. If forecast is yes but observed is no, the event is classified as a false alarm. If forecast is no but observed is yes, the event is classified as a miss. If both forecast and observed are no, the situation is classified as a correct nonevent.

\begin{tabular}{|c|c|c|c|}
\hline & & \multicolumn{2}{|c|}{ Observed } \\
\hline & & Yes & No \\
\hline \multicolumn{4}{|c|}{ Low wind $\left(<35 \mathrm{~km} \mathrm{~h}^{-1} ; N=122\right)$} \\
\hline \multirow[t]{2}{*}{ Forecast } & Yes & 24 & 18 \\
\hline & No & 18 & 62 \\
\hline \multicolumn{4}{|c|}{ Moderate wind $\left(35-45 \mathrm{~km} \mathrm{~h}^{-1} ; N=122\right)$} \\
\hline \multirow[t]{2}{*}{ Forecast } & Yes & 52 & 21 \\
\hline & No & 20 & 29 \\
\hline \multicolumn{4}{|c|}{ High wind $\left(>45 \mathrm{~km} \mathrm{~h}^{-1} ; N=122\right)$} \\
\hline \multirow[t]{2}{*}{ Forecast } & Yes & 1 & 6 \\
\hline & No & 7 & 108 \\
\hline
\end{tabular}

2000). We used data from India Meteorological Department (IMD) wind forecasts and fishing advisories, available on the IMD Meteorological Centre, Thiruvananthapuram, website (https://mausam.imd.gov.in/thiruvananthapuram/). When wind speed touches $40 \mathrm{~km} \mathrm{~h}^{-1}$, IMD issues advisories of "caution" or "do not venture into the sea" (NVIS). IMD communicates severe weather using their website, via mass media, through government departments dealing with fisheries and ports, and via the State Disaster Management Authority (SDMA). Indian National Centre for Ocean Information Services (INCOIS) issues wave height forecasts via their website and through special bulletins to community media groups and harbors. INCOIS issues high wave alerts when wave height touches $3.5 \mathrm{~m}$ and/or swell height reaches $3 \mathrm{~m}$.

Since IMD produces wind forecasts for an area of over $100 \times$ $100 \mathrm{~km}^{2}$ in a categorical way, we used categorical forecast evaluation by comparing forecasts with observations (Jolliffe and Stephenson 2003; Wilks 2005). We calculated the number of days IMD has issued such forecasts throughout the monsoon season $(n=122)$ to understand the impact of these advisories on fishing. We undertook a quantitative analysis of forecast accuracy, supplemented by qualitative interview data (discussed below). We triangulated our findings by drawing on follow-up focus group discussions. Ocean surface winds are measured by scatterometers. Indian Space Research Organisation (ISRO) Scatterometer Satellite-1 (SCATSat-1) provides spatial data with resolution of $25 \mathrm{~km} \times 25 \mathrm{~km}$ (Bhowmick et al. 2019; Jaiswal et al. 2019). We used these data averaged over a $100 \mathrm{~km} \times 100 \mathrm{~km}$ domain to match with IMD forecast domain and tested forecasts for three categories of wind forecasts: below $35 \mathrm{~km} \mathrm{~h}^{-1}, 35-$ $45 \mathrm{~km} \mathrm{~h}^{-1}$, and above $45 \mathrm{~km} \mathrm{~h}^{-1}$ (in line with categories used by IMD advisories).

Using a contingency table composed of forecast and observation values in each category, we conducted the following tests for forecast accuracy (Jolliffe and Stephenson 2003; Wilks 2005). Proportion of correct forecasts (PCF) denotes hits (correct forecasts) as well as nonevents that were correctly predicted (see Table 1 ): 


$$
\mathrm{PCF}=(\text { hits }+ \text { correct negatives }) / \text { total }
$$

Probability of detection (POD) looks at what fraction of actual events were correctly forecast. The test uses the following formula, with values ranging from 0 to 1 and a perfect score of 1 :

$$
\text { POD }=\text { hits } /(\text { hits }+ \text { misses }) .
$$

Probability of false detection (POFD) looks at the fraction of the observed nonevents that were incorrectly forecast as events:

$$
\text { POFD }=\text { false alarms } /(\text { correct negatives }+ \text { false alarms }) .
$$

False alarm ratio (FAR) denotes the fraction of the predicted events that actually did not occur:

$$
\mathrm{FAR}=\text { false alarms } /(\text { hits }+ \text { false alarms }) .
$$

Further, critical success index (CSI) measures how well the forecast events correspond to the observed events, with a range of $0-1$, with 1 indicating a perfect score.

$$
\mathrm{CSI}=\text { hits } /(\text { hits }+ \text { misses }+ \text { false alarms }) .
$$

Denoting reliability, bias measures the ratio of the frequency of forecast events to the frequency of observed events. It tests whether there is overforecasting (forecast is more than the actual occurrence), or underforecasting (forecast is less than the actual). In the metrics, 1 shows an absence of bias; values of less than 1 indicate underforecasting, and values of more than 1 demonstrate overforecasting:

$$
\text { bias }=(\text { hits }+ \text { false alarms }) /(\text { hits }+ \text { misses }) .
$$

As a popular test for forecast skill, the Heidke skill score (HSS) measures fractional improvement over random chance. The range of the HSS is from $-\infty$ to 1 . Negative values indicate that the chance forecast is better, 0 means no skill, and a perfect forecast obtains a HSS of 1. In a simplified form, the formula below is used in the HSS:

$$
\mathrm{HSS}=2(a d-b c) /[(a+c)(c+d)+(a+b)(b+d)] .
$$

where $a$ denotes hit, $b$ denotes false alarm, $c$ denotes miss, and $d$ denotes correct negative.

Wave forecasts are generated using a third-generation spectral wave model, which is configured and setup at INCOIS (Balakrishnan Nair et al. 2013). We use data from the wave rider buoy at Colachel (the one nearest to the study area) supplemented by satellite data. Further, to observe local waves, we use wave analysis data available from global ocean wave analysis and forecast products, on a projection hosted by the Copernicus Marine Environment Monitoring Service (https://marine.copernicus.eu/). This EU-based service assimilates data from a global network of ocean buoy observations as well as satellite altimeter observations. These data are also averaged for a $100 \mathrm{~km} \times 100 \mathrm{~km}$ domain matching forecasts. Satellite wave data also inform our qualitative analysis, to observe the decisions fishers make when faced with different sea states.

\section{b. Qualitative data}

In the initial phase, discussions about safe fishing were held with an open sample of fishers. From this, 5 boats in each village formed the purposive sample of fishers willing to engage with the project to provide data on decision-making. All meetings and ensuing focus group discussions were facilitated by the Sneharam Centre for Social Research and Action, a Jesuit organization in Anchuthengu, which enjoys local trust. Sneharam was able to give access to fishers in both Anchuthengu and Poonthura, via embedded networks in the fisher community. The project required a cohort of boats that would regularly give us reliable data for the entire duration of the monsoon season. The sample in each place was selected for two main criteria: fishers' consent to give full access to decision-making processes; craft being representative of the 30-34 feet $(\sim 9-10 \mathrm{~m})$ boats that can go up to $50 \mathrm{~km}$ offshore (and occasionally beyond that)—which form the majority of the craft in both of the study villages.

We tracked fishing journeys of the 10 sample boats for 122 days from 1 June to 30 September 2018. Each boat had a stable crew ranging from four to eight fishers, who went to fish on day or night trips. A team of three local research assistants-introduced to us by Sneharam-filled printed copies of custom-made log sheets, produced in collaboration with the fishers from the boats being tracked daily. Log sheet data included time and location of the boats launching, fishing, and landing; fish catch; weather; and seastate observation made by the crew, along with a note on forecast use. To aid easy access and understanding of marine weather forecasts, we supported and promoted an online and phone-in weather service in the local language, Malayalam. This was Radio Monsoon (radiomonsoon.in) and was based on vernacular readings and interpretations of IMD and INCOIS forecasts ${ }^{7}$ (Deri and Sundaresan 2015; Slawson 2017).

To gain deeper insights into user perceptions of the weather, risks, and forecasts, we used data from discussions with fishers-by way of 4 focus group discussions, 10 semistructured interviews, and numerous informal conversations in each study village-during fieldwork conducted between February and September 2018. The focus groups discussed local climatic and environmental features; weather-related hazards; the risks involved in fishing; perceived changes in hazards and risks across the year, season, day, and night and at different distances from the shore; available forecasts and their level of forecast use; fishers' own understanding of dynamic weather conditions and sea state; and fishers' everyday strategies for dealing with risks. One focus group from each village focused on forecast quality and usage. Each focus group comprised 8-12 participants, mostly crew members from the boats we tracked. Two experienced

\footnotetext{
${ }^{7}$ Besides regular IMD and INCOIS feeds, Radio Monsoon used additional information. The Indian Ocean and Southern Hemisphere Analysis Centre provides marine forecasts online. Under the Global Maritime and Distress Safety System weather forecasts are given two times per day through a network of cyclones warning centers attached to selected IMD weather stations including the one in Thiruvananthapuram. INCOIS issues daily Ocean State Forecast services online, through email to radio stations, and as text messages to fishers who subscribe (Balakrishnan Nair et al. 2013).
} 
fishermen, who were not part of the boats we tracked, were also invited to the focus groups in each village. A moderator and a researcher, both fluent in the local language, facilitated these discussions. Later, the transcripts of the digital recording were analyzed along with field notes (Krueger and Casey 2000).

The interviews covered the above aspects-of weather, sea state, attitudes to risk, forecast usage-but with focus on personal experiences and choices. All transcripts were thematically coded and analyzed. Each interview lasted about an hour with questions also including details of fish catch, market access, fish price, and the fishers' income needs. The log sheets contained numeric entries as well as short diary notes. Their quantitative part was analyzed in Excel, along with tables relating to the fishing decisions of each boat and the notes explaining the rationale behind these discussions. The feedback gathered from the fishers were conveyed to various forecasting agencies via email, two formal research meetings and through a Policy Brief (Osella et al. 2019). Qualitative data collected via focus groups and interviews were further contextualized and made more robust via triangulation using informal conversations with fishers.

Further, we categorized the monsoon season into three sets of days based on the Beaufort scale (WMO 1998)-(i) calm (wind speed $<19 \mathrm{~km} \mathrm{~h}^{-1}$; wave height $<1 \mathrm{~m}$ ), (ii) moderate (wind speed: $20-39 \mathrm{~km} \mathrm{~h}^{-1}$; wave height: $1-3 \mathrm{~m}$ ), and (iii) high (wind speed $>40 \mathrm{~km} \mathrm{~h}^{-1}$; wave height $>3 \mathrm{~m}$ ). ${ }^{8}$ We use this scale as a simple, standardized measure of potential safety risk that the fishers face in the sea. Case studies of three episodes (8-12 June, 9-13 July, and 12-16 August 2018), each lasting for 5 days of considerably high wind and large waves, were used to check the level of forecast usage, in terms of how the fishers used the forecasts. The satellite measurements (SCATSAT-1 for wind and Copernicus for waves) take into account values for different distances from the shore on a $25 \times 25 \mathrm{~km}^{2}$ grid map.

\section{Findings}

\section{a. Forecast verification}

Figure 2a shows high accuracy in general due to comparatively rare occurrence of strong wind events (above $45 \mathrm{~km} \mathrm{~h}^{-1}$ ) and more frequent occurrence of slower wind $\left(35-45 \mathrm{~km} \mathrm{~h}^{-1}\right)$, in line with monsoon climatology. Therefore, forecasting some of the rare events and not forecasting nonevents appear to give a sense of overall accuracy. Probability of detection (Fig. 2b) is the highest for the $35-45 \mathrm{~km} \mathrm{~h}^{-1}$ range, the most frequently forecast range. Probability of detection of high wind $\left(>45 \mathrm{~km} \mathrm{~h}^{-1}\right)$ events is low. At the same time, the false alarm ratio (Fig. 2c) with regard to $>45 \mathrm{~km} \mathrm{~h}^{-1}$ wind events is high, as the figure considers false hits in relation to total events observed. In terms of accuracy, high wind events are often wrongly predicted or missed altogether. Critical success index (Fig. 2d) appears to be poor for high wind events but better for the mainstay of forecasts, that is, wind speeds between 35 and $45 \mathrm{~km} \mathrm{~h}^{-1}$.

\footnotetext{
${ }^{8}$ The term "high wind" here denotes wind above $40 \mathrm{~km} \mathrm{~h}^{-1}$ as local forecasts for small boats indicate and not the category of high wind (above $50 \mathrm{~km} \mathrm{~h}^{-1}$ ) used in the Beaufort Scale.
}

The bias test for reliability (Fig. 2e) suggests that forecasters tend to overforecast wind speeds of $35-45 \mathrm{~km} \mathrm{~h}^{-1}$ range and underforecast higher wind speeds. Such forecast bias could happen because of data bias in which recent trends (such as wind speeds of a certain level) tend to influence the judgement made on forecasts, or when forecasters try to avoid the risk of missing an event. Heidke's skill score (Fig. 2f) shows the lowest skill for wind above $45 \mathrm{~km} \mathrm{~h}^{-1}$, as compared with other categories, suggesting more attention is needed for wind forecasts. As such, the accuracy and relevance of wind forecasts above $45 \mathrm{~km} \mathrm{~h}^{-1}$ require a closer look. Frequent high wind events over some parts of the sea close to Kerala often lead to generalized cautionary advisories from the forecasters and fishing restrictions by the government. These advisories, however, are not necessarily relevant to small boats engaged in fishing in local waters. In conclusion, forecasts need to be more specific for smaller areas that are exposed to different wind regimes. In the qualitative sections below, we look at forecast usage, especially under rough weather.

Figure 3 shows that offshore waves are invariably higher than waves closer to the shore. The wave height remained above $2 \mathrm{~m}$ on most days. Frequently, the waves exeeded $3 \mathrm{~m}$ offshore. As such, in a span of 122 days, 57 high wave/swell alerts were issued (Table 2). Although there were high waves offshore, waves seldom crossed the 3-m mark nearshore-within $20 \mathrm{~km}$ from the shore-where most fishers usually operate during the monsoon season. This difference in wave heights shows that the customized local wave forecasts issued by INCOIS through different channels, including Radio Monsoon, are relevant. In focus group discussions and interviews, the fishers demanded more accuracy of wave forecasts. Fishers of Anchuthengu, for instance, faced high waves even close to their harbor, and all of the skippers of the boats we tracked checked whether they could get the timing of the waves right. ${ }^{9}$ In the next sections we compare these forecasts with satellite observations.

An analysis of wind and wave advisories (that restrict fishing) along with satellite observations of wind speed (Fig. 4) shows that most of the "Do not venture into the sea" (NVIS) advisories were issued for days of moderate wind-there were 22 such advisories. Apart from these, only four NVIS advisories were issued on windy days. In effect, IMD asked the fishers not to fish on over a fifth of the monsoon days. On the contrary, for nine days of wind above $37 \mathrm{~km} \mathrm{~h}^{-1}$, no special alerts or NVIS were given. Overall, such experiences feed into the fishers' perception that alerts and advisories are not always based on a definitive set of forecast parameters.

\section{b. User-based assessment of forecast usage}

\section{1) ASSESSMENT BASED ON CASE STUDIES OF WINDY DAYS}

To understand the level of forecast usage, we first look at three case studies of windy days, through qualitative methods. The windy period in June saw one IMD note for caution (8 June) with

\footnotetext{
${ }^{9}$ The design of the nearby Muthalappozhi harbor-that Anchuthengu fishers use-causes dangerously high waves during the monsoon season (Unnikrishnan 2020).
} 


\section{a. Proportion of correct forecasts}

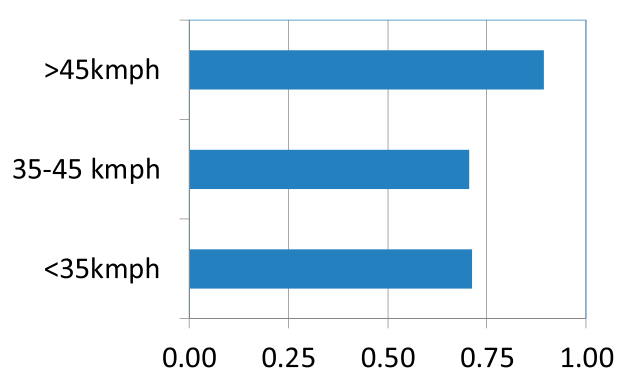

c. False alarm ratio

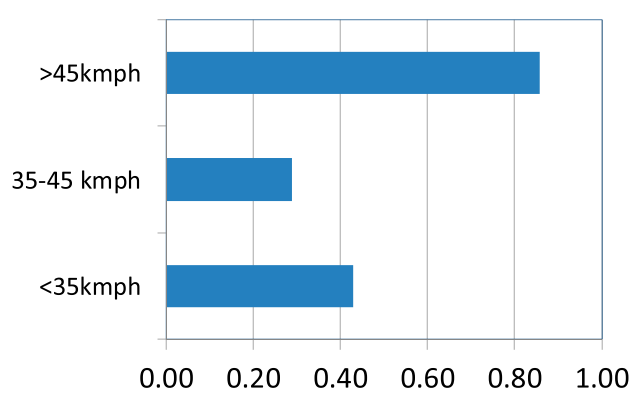

e. Bias

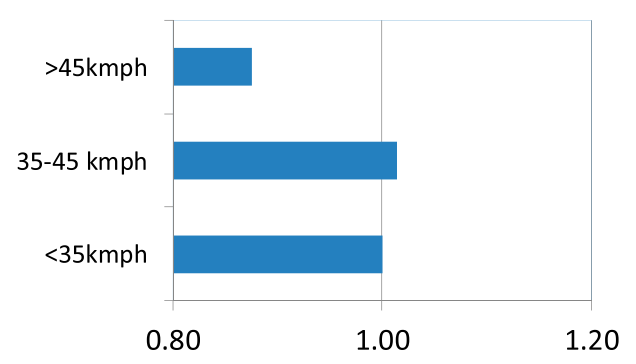

b. Probability of detection

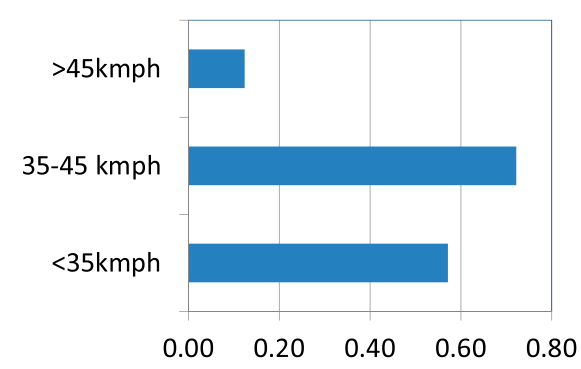

d. Critical success index

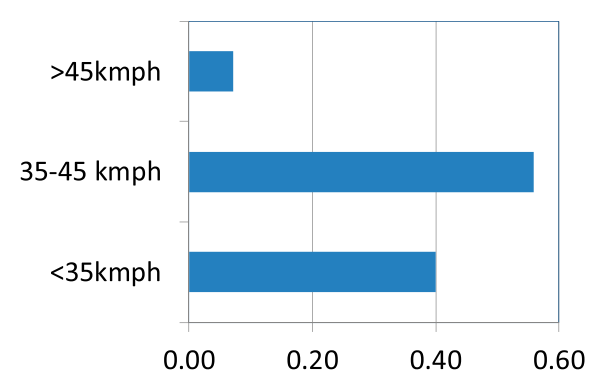

e. Heidke's skill score

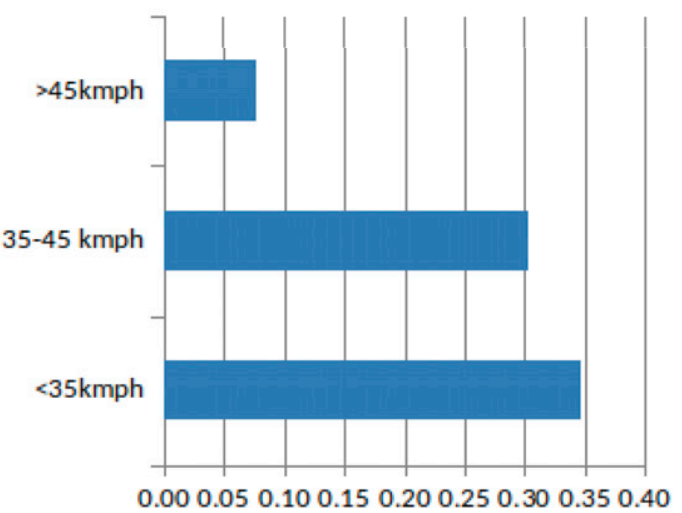

FIG. 2. Forecast verification.

forecast for $35-45 \mathrm{~km} \mathrm{~h}^{-1}$ wind, and subsequent NVIS advisories (9-12 June) with forecasts for $40-50 \mathrm{~km} \mathrm{~h}^{-1}$ wind. INCOIS issued high wave alerts for 9-11 June.

On 8 June, in Poonthura, four of the five boats that we tracked went to fish. The catch was below $60 \mathrm{~kg}$, except for one boat that fetched $150 \mathrm{~kg}$ of fish. The following day (9 June), there was a church announcement restricting fishing; 10 June was a Sunday - a holiday. On the fourth day (11 June), despite the NVIS, four of five boats in Poonthura were operational, two of them fetching 200 and $150 \mathrm{~kg}$ of fish each. Four boats ventured out on 12 June, two of them fetching $180 \mathrm{~kg}$ fish each. In Anchuthengu, the fishers launched four of the five boats on 8 June. There was no fishing on 9 June, when there was a church announcement restricting fishing. Only one boat went to fish on 11 June, with a catch of $60 \mathrm{~kg}$; nobody went on 12 June. The fishers here said they would have liked to see a more detailed forecast. "They should clearly mention the time, 'mileage' (local slang for distance from the shore), and duration of the wind," said one skipper. A boat owner from Anchuthengu noted that he stayed within the safe limits and heeded the church's warning.

The windy period of July had only one day with NVIS advisory (on the fifth day, 13 July) and the fishers did not go to fish that day. The forecast was for $35-45 \mathrm{~km} \mathrm{~h}^{-1}$ winds. Satellite observation shows that closer to the shore the wind remained less than $30 \mathrm{~km} \mathrm{~h}^{-1}$ (Fig. 5). There were waves of 
Muthalappozhi
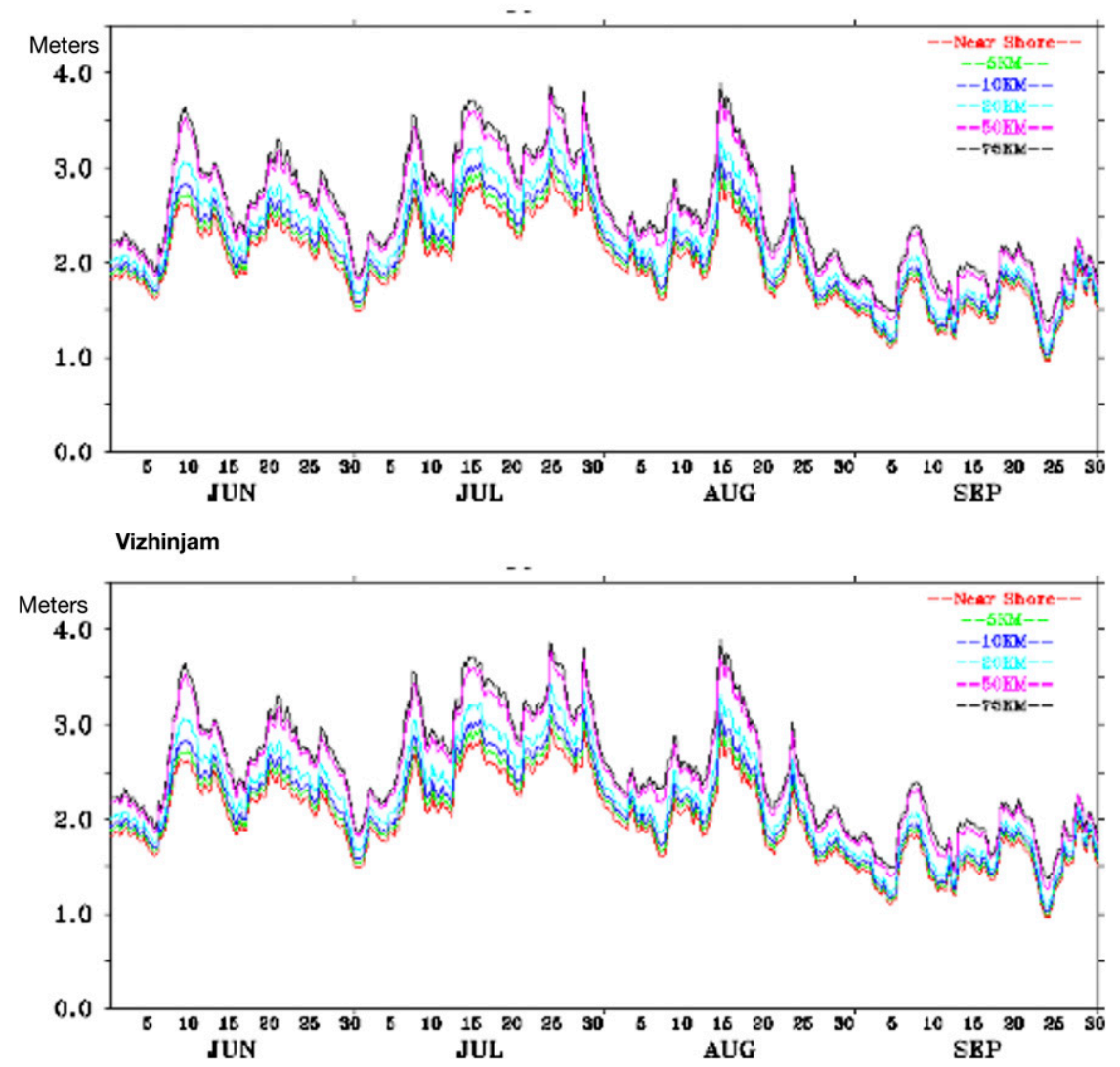

FIG. 3. Wave forecasts for different distances from harbors.

2.5-3 m. In Poonthura, the fishers operated all five boats within $6 \mathrm{~km}$ from the shore. They all had a very good catch on 9 July. One boat reported a bumper catch of $3600 \mathrm{~kg}$, and the lowest figure was $780 \mathrm{~kg}$. The fishers said they had made their own assessment of the sea state and ignored the forecasts. In Anchuthengu, three boats were operational on all five days, sticking within $13 \mathrm{~km}$ from the shore. The fourth boat was operational throughout, except on $10 \mathrm{July}$ when the owner noticed "rough sea." The remaining boat was launched only on 12 July, and the boat owner said he listened to the forecast for wind but decided to take the risk anyway. On the fourth day, he wanted to go, but he could not gather enough crew. The selected period in August had no NVIS advisory or INCOIS wave alert. The forecast, however, was for wind of $35-45 \mathrm{~km} \mathrm{~h}^{-1}$, which occurred offshore on 14 and 15 August. Coastal waters were relatively calm. In Poonthura and Anchuthengu all boats went to fish on 13-14 August. In Poonthura, three boats went out on 16 August, but none were launched from Anchuthengu. Four skippers said they did not go because of the forecast of "heavy wind" and "large waves."

Skippers of two boats in Poonthura said they regularly checked forecasts from private agencies online. Poonthura fishers also said they exchange information on weather over mobile phones and wireless sets, as they often traverse long distances to fish-especially farther south, where the wind is stronger than elsewhere in the district.

Overall, the observations show that wind and wave patterns changed distinctly across different distances from the shore, with the coastal waters remaining comparatively safer. The fishers seem to have made their own assessment of the sea state, rather than relying solely on the forecast; however, the church announcements seem to have a significant impact on forecast usage and fishing decisions. Fishers of Poonthura went to fish on $70 \%$ of the days when there was an NVIS advisory, and close to $60 \%$ when there was an alert. Fishers of Anchuthengu went to fish only on $40 \%$ of the days when there was an NVIS advisory, and close to $50 \%$ when there was an alert. Veteran fishers explained that this difference might be due to the skill and

TABLE 2. Days on which INCOIS issued high wave alerts during monsoon.

\begin{tabular}{lc}
\hline \hline Wave alert (waves $>3.5 \mathrm{~m})$ & Swell alert $($ swell $>3 \mathrm{~m})$ \\
\hline 7-15 and 16-23 Jun (17 days) & 14-16 Jun (3 days) \\
2-4 and 6-31 Jul (29 days) & \\
17-20 Aug (4 days) & \\
26-29 Sep (4 days) & \\
\hline
\end{tabular}




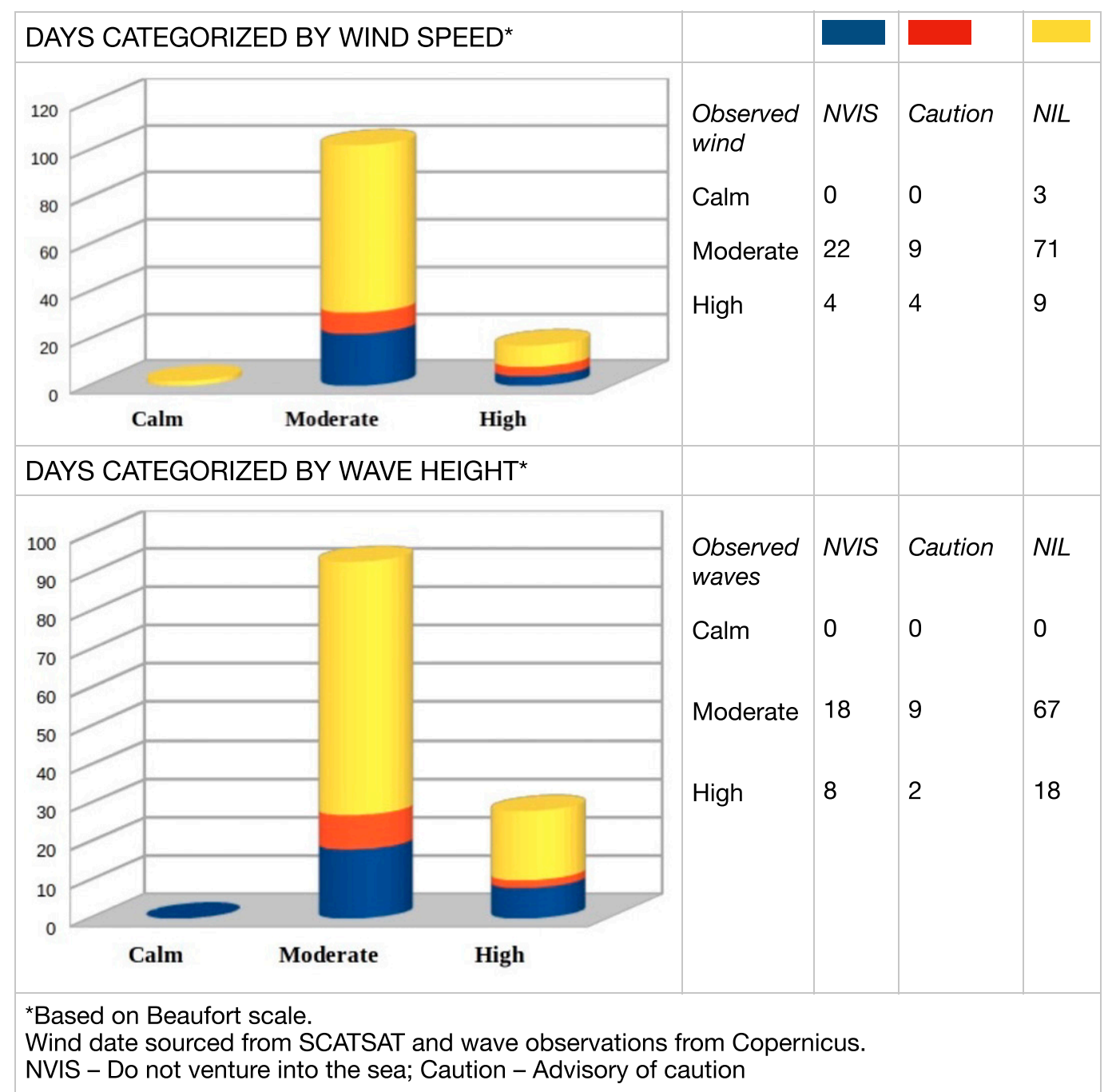

FIG. 4. Advisories on calm, moderate, and high wind/wave days.

experience of Poonthura fishers in working under a stronger wind pattern, and to their more risk-prone modes of fishing.

\section{2) ASSESSMENT BASED ON FOCUS GROUPS, INTERVIEWS, AND CONVERSATIONS}

To gain more insights into the fishers' engagement with forecasts and alerts, we consider concerns that emerged from analysis of focus group discussions, semistructured interviews and conversations.

Fishers in both Poonthura and Anchuthengu listen to radio and watch television for forecasts. IMD's occasional marine weather news bulletins (with INCOIS inputs) in the mass media usually consist only of alerts about wind/wave events and approaching storms. District-level information is available online from INCOIS website, but most fishermen in our study group did not access this information. Younger fishers, especially those under 25, however, increasingly use the internet and social media for forecasts. Once they are offshore, the fishers do not get ready access to weather forecasts, except through basic mobile phones that work up to
$15 \mathrm{~km}$ from the shore. Some young fishers in Poonthura (and other southern villages) have low-end VHF radio sets with a range of about $20 \mathrm{~km}$, used mostly for communication between boats about fish catch and sea state. Local churches ${ }^{10}$ and social organizations often relay extreme weather advisories and alerts over their loudspeakers. Importantly, parish committees-which include local priests as well as elected representatives of fishers, fish traders, and entrepreneurs - can issue fines on those who breach locally agreed arrangements concerning catching and selling fish.

In Poonthura, the fishers said that, although they use wireless to share weather information with peers, it is unreliable.

\footnotetext{
${ }^{10}$ Church announcements are based on advisories from state government agencies, mainly the Fisheries Department and the Coastal Police. The government alerts are based on IMD forecasts and alerts from the State Disaster Management Authority, which consults different sources of weather information and makes its own risk assessment.
} 

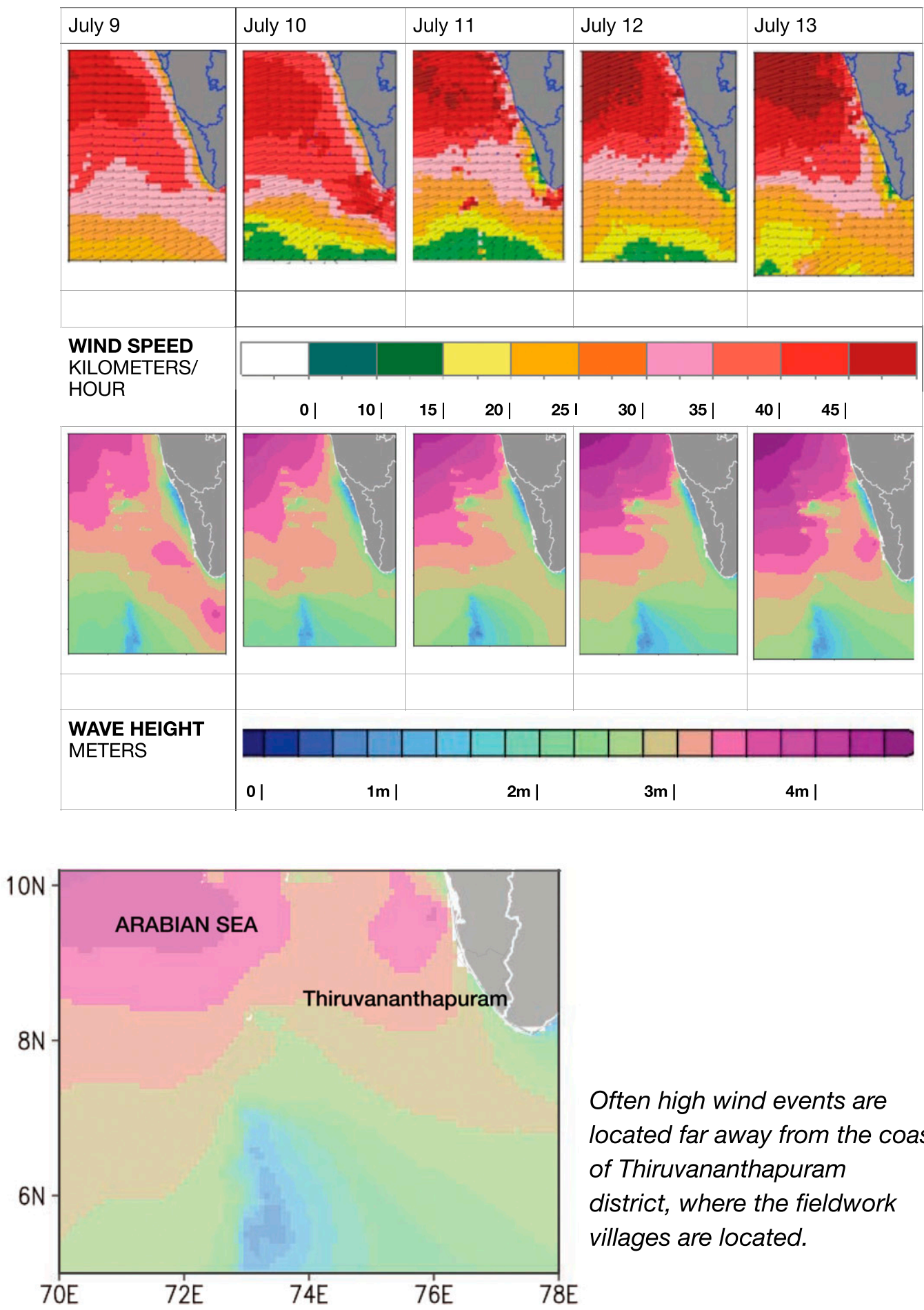

Often high wind events are located far away from the coast of Thiruvananthapuram district, where the fieldwork villages are located.

FIG. 5. High wind and wave event of July 2018.

"Wireless is the first thing that stops working when there is rough weather," said a boat owner in a focus group. The fishers prefer more robust wireless sets that can be used in rough weather in their open boats. However, wireless sets are not yet freely available in the local market and the choice is limited. In
Anchuthengu, two skippers recommended the setting up of a community FM radio station on the coast. Anchuthengu fishers also preferred daily weather information over loudspeakers at the harbor. Overall, artisanal fishers underscored the need for more localized, timely and easily accessible weather 
information services. In both places, the fishers stressed the importance of church loudspeaker systems as an important mode of forecast dissemination during extreme weather. "We go by what the church says," said a fisherman in Anchuthengu, reflecting a common opinion shared across interviews in both villages. The fishers said that most of them respected the parish priest and listened to his advice.

In focus groups, most participants said that existing basic weather information available in Malayalam vernacular media is easier to understand than its English language counterparts, but that it lacks relevant details. However, the EnglishMalayalam media translation process makes use of a formal Malayalam that uses high register Sanskrit-based terms that are inaccessible to some fishers with no education beyond primary school. "It might help if they speak our language and tell us about it in more detail," said a Poonthura fisher in a focus group. "Explain it to us like a brother would do," demanded an elderly fisherman in Anchuthengu. However, younger fishers said they were comfortable with all modes of updates, including abbreviated texts, online maps, and graphics. In Anchuthengu, all the fishers said they were concerned about high waves at the Muthalappozhi harbor that make boat launching and landing risky during the monsoon, leading to frequent accidents. As a result, fishers look for details of wind and wave timings, so that they could cross the harbor during "safe windows."

The most frequent comment we heard was that forecasts "need to be clearer," and that "they sound alike all the time." Our quantitative analysis supports this observation, by demonstrating the overforecasting of moderate wind and the missing out of some wind events. While fishers regarded forecasts to be somewhat accurate, they also argued that at times forecasting agencies failed altogether to predict the development of major weather events, and, consequently, to issue timely warnings. At the same time, fishers pointed out that government agencies-IMD, Fisheries Department, and SDMAoften issued warnings and restrictions on fishing that fishers regarded as unnecessary or inappropriate. Such restrictions might include a total ban on fishing sometimes enforced by the police or local churches. Indeed, the state government can deny compensation to fishers in the case of accidents at sea when fishing restrictions have been imposed. The government also issues advisories recommending caution, instructing fishers, for instance, to keep away from particular sea areas, or to return to the shore as soon as the weather turns for the worse.

Our quantitative data support the fishers' observations, with clear evidence of overforecasting for $35-45 \mathrm{~km} \mathrm{~h}^{-1}$ range. In focus groups, in both villages, fishers said that the apparent proliferation of NVIS and alerts sought to compensate for the inaccuracy of forecasts. "They are not sure what is going to happen," a fisher suggested, "so they tell us not to go to sea." Others argued that safety warnings have increased substantially after the inadequate forecasting of Cyclone Ockhi. "Now they

\footnotetext{
${ }^{11}$ Cyclone Ockhi quickly intensified and turned closer to Thiruvananthapuram, deviating from the forecast storm track. There were also failures in timely forecast dissemination (Roshan 2018).
}

are just too careful," said one young fisher. In Anchuthengu, during a focus group on weather-related hazards, two middleaged fishers were vocal about fishing restrictions. "Just give us weather forecasts, don't tell us what to do," said one. The other complained that fishers have given plenty of feedback on forecasts in formal meetings with the forecasters, without much subsequent improvement in forecasts.

Our qualitative data suggest that, regardless of reservations, fishers do access and use forecasts as part of their decisionmaking toolbox. "If they say there'll be wind, there'll be wind out there, somewhere, but not necessarily near our shore," a fisher told us, suggesting that forecasts need to be more localized and relevant. A fisher in his mid-30s (in age) said that, while he listened to forecasts - especially on windy days-he did not necessarily adhere to them. "For me, it is for reference. If there is forecast for high wind I will be cautious; and I can return if the wind persists." A hook-and-line fisher in his 60s (in age) in Poonthura said that he had experienced 40 and $45 \mathrm{~km} \mathrm{~h}^{-1}$ wind frequently. "In my youth, I never used to listen to forecasts. But now the wind is becoming worse, so we listen to forecasts."

At the same time, the interviews in Anchuthengu suggest that most fishers prefer not to fish on windy days. "If the wind is $40 \mathrm{kmph}$ we prefer not to go," said one of the skippers. "Still we take a chance if there is a lot of fish. Then there are fishers who do not care-they just go out in all weather." Fishers notice that forecast usage has dramatically increased after Cyclone Ockhi, in which Poonthura suffered the most in the state in terms of casualties (Roshan 2018). "We thought we knew the sea but that day [of the cyclone] changed it all," said a veteran fisher in Poonthura. Nobody from Anchuthengu went out to fish during the cyclone. "The wind was bad, and there was no fish here," a skipper explained.

Decisions to go out fishing or to stay back, or to return when the weather turns foul are informed by assessments of weather forecasts, observations based on experience, and information shared over social networks. The skills, experience, courage and luck of skippers and crews lead some boats to be more willing to take risks. Many fishers told us that, "If there is fish, we will go; if there is no catch, then it is not worth the risk." A skipper in Anchuthengu said he diligently listened to forecasts; but he qualified his statement: "It's like this-if the forecast says there is 35 or $40\left[\mathrm{~km} \mathrm{~h}^{-1}\right]$ wind out there, we say it's too risky to go; but if we know that there is a lot of fish we just say, well, let's give it a shot." This risk taking appears to be more pronounced among the large proportion of fishers facing financial precarity or instability-of whom, we note, there are many. "If I get a bonus catch, I can pay off debts accumulated to build my new house," said a fisher in his mid-30s, who had lost his old house due to coastal erosion. In other words, availability of plentiful fish and economic pressures play an important role in artisanal fishers' decisionmaking.

\section{Discussion and conclusions}

Our study suggests that, while forecasts might need to be more accurate, localized, and more time sensitive, the involvement and intervention of organizations such as local churches and 
community media might improve users' access to and usage of forecasts. At the same time, forecasts alone do not appear to determine decision-making on fishing. Artisanal fishers adapt and use - or decide not to use-forecasts in the way they see fit, gathering weather information along the way through a variety of sources, interpreting it based on their experience and practical knowledge. Such a "process of tinkering" (Daipha 2012, p. 17) leads to contingent decisions and contextual improvisations. Customized and localized forecasts with feedback options do have a role to play in making forecasts more accessible, relevant, and useful as the focus group discussions suggest. However, even such interactive forecast usage does not necessarily lead to adherence to forecasts and warnings. Our observations contradict the assumptions of those who suggest that "deciding whether the weather is going to be fishable" is the primary concern of fishers (Daipha 2015b, p. 182). More than the weather itself, often it is the availability of fish, and the hope of securing income via a bonanza haul that influences fishers' decision under uncertain-and even hazardous-weather conditions to go to sea or not.

The data we presented highlight the shortcomings of categorical weather advisories and fishing restrictions based on them, as well as the potential limitations of interventions either directed toward "educating users" (Daipha 2012, p. 21), or improving communication (Lemos et al. 2012) for better understanding and use of weather forecasts. Over the years, artisanal fishers have been the object of the development interventions of government agencies and nongovernmental organizations (NGOs), from the modernization of fishing-with new technologies, efficient fishing methods, better markets, and easier loans - to the promotion of labor rights and access to education and civic services. Together with the promotion of literacy and education throughout the state of Kerala, the longterm impact of these interventions makes it implausible to posit an ontological clash between fishers" "traditional" knowledge and skills (see, e.g., Mathur 1977; Hoeppe 2008, 2011; Santha et al. 2014; Panipilla 2015; Sundar 2019) and the scientific endeavor of weather forecasters. And yet, in Kerala, artisanal fishers' socially located evaluation and approach to weather hazards and risks are normally dismissed by forecasters and government agencies as the reckless behavior of a badly informed-if not altogether ignorant-fishers' population, routinely stereotyped and marginalized by virtue of their low social status. (Kurien 1985; Subramanian 2009). South Indian artisanal fishers are, to use the words of Finnis et al. "sophisticated weather consumers" adept at "working the weather" with new technologies and knowledge (Finnis et al. 2019, p. 329; Saldanha et al. 2020; Bulengela et al. 2020). In other words, while artisanal fishers are turned into the object of pedagogical interventions and training to make them yield to the "scientific truth" of meteorology and formal risk assessments, their agency in determining how to best prepare and when to go to sea is altogether undermined.

This, in turn, underscores the ways artisanal fishers differ-at times dramatically-from the forecasters in how weatherrelated hazards are assessed and managed. For the forecasting agencies, the potential risk of weather events is determined by the intensity, evolution, trajectory and impact of weather systems, assessments that are then passed on and disseminated along an established bureaucratic chain of governance. The focus here is on the contours and behavior of a hazardous weather event against the potential risks it might constitute for the physical and social environment involved and disseminating the forecasts with adequate lead time (Pattnaik 2019; Montz et al. 2017). For fishers in our two research areas, the actual dangers ensuing from hazardous weather are evaluated and established in a somewhat different, and perhaps more complex, fashion-one that focuses on the management or containment of uncertainty, rather than on the elimination of risk. For the fishers, working in a risk-prone environment, decision-making is a practical activity based on "available heuristics, techniques, and resources" (Daipha 2015b, 197-198) that emerges at the interstices of precarious livelihoods on the geographical and social margins of Kerala.

We find that fishers' trust in the reliability of weather information is clearly an issue. Forecasts are largely correct, but they need attention, especially in the context of wind above $45 \mathrm{~km} \mathrm{~h}^{-1}$. While there is overforecasting on medium-level wind, there are frequent false alarms and misses of such wind events. False alarms can lead to unnecessary loss of fishing days, and more seriously, misses can impact crew safety.

Forecast dissemination often remains patchy, especially at the last mile. Indeed, fishers in our research areas demanded that weather bulletins be communicated in a language and style accessible to them, and asked for more finely tuned, localized and timely forecasts relevant for different types of fishing at different distances from the shore. They sought information on specific sea areas relevant to their work, precise time frames for beginning and end of wind/wave spells, details of offshore wind patterns at various distances from the shore, and their likely impact for small boats. External groups such as community media organizations can make forecasts more accessible and tailored for different sets of users. At the same time, fishers are more open to follow advisories from local bodies that have historical (moral and practical) authority over local communities - such as parish churches-rather than those suggested or enforced by state authorities and bureaucracy with which fishers continue to have fraught or conflictual relations.

However, there are limits to what forecasts can do. Fishers are sophisticated users of weather information. They consult multiple sources, discuss the day's weather and sea state with peers and elders, and debate the merits and demerits of fishing under rough weather. Weather forecasts are just one of the tools artisanal fishers deploy; not simply to decide as to whether to go to sea or not, but also to manage potential risks, allowing them to prepare for fishing under hazardous conditions - deciding, for instance, timing, length and distance of expeditions and what gear to take. Fishing decisions are complex, and they take into account costs and benefits involved in each trip. Often it is the availability of fish that drives decision-making rather than the forecast. The economic needs of fishing households are an important driver in fishers' decision concerning whether to go to sea or not under adverse weather conditions. 
Artisanal fishers do not (always or necessarily) adhere to forecasters' do-not-venture-into-the-sea injunctions (aimed at avoiding risk at all costs) but seek instead more nuanced and timely weather information to help them negotiate risk during the hazardous and potentially highly remunerative monsoon season. Forecasters, however, miss this idea of sophistication, in part because their assessment of risks differs from that of the fishers. That is, while forecasters' aim is to reduce risk of accidents at sea by preventing fishing altogether under particular meteorological circumstances-especially in the presence of strong winds - fishers are aware of, but prepared to negotiate, possible risks in order to make a good catch of fish whenever they can.

In recent years, coproduced and tailor-made forecasts that combine scientific observations from experts with those gathered by popular science groups, citizen observers, and the users themselves (mediated by boundary organizations and information brokers such as community media) have been showcased as the way forward in climate action (Hov et al. 2017). Coproduction might partly solve the problems in the way of effective forecast usage. And yet, improving forecast usage also requires better forecast skill and efforts to facilitate wide dissemination of tailor-made weather information products to user groups and train them to interpret and effectively use scientific knowledge (Patt and Gwata 2002). Most importantly, however, forecasts and their dissemination need to be sensitive to risk cultures and livelihood imperatives of artisanal fishing communities.

Acknowledgments. This research was supported by generous grants from the Sussex Sustainability Research Programme, Royal Geographical Society and the UKRI Global Challenges Research Fund (Grant ES/T003103/1). We thank S. Balachandran, deputy director general of the India Meteorological Department, Sekhar L. Kuriakose, member secretary of the Kerala State Disaster Management Authority, Benny Chiramel SJ, director of Sneharam Centre for Social Action and Research, Anchuthengu, Thiruvananthapuram, and their colleagues and local fishers of Anchuthengu and Poonthura for their help at various stages of this study. Gram Vaani contributed to Radio Monsoon's technology and dissemination. At Sussex, Kate Howland (Informatics) and Pedram Rowhani (Geography) contributed to the study design.

\section{REFERENCES}

Alex, D. R., 2018: Religious identity at the crossroads. Econ. Polit. Wkly., 53, 42-49.

Ashni, A. L., and R. Santhosh, 2019: Catholic Church, fishers and negotiating development: A study on the Vizhinjam port project. Rev. Dev. Change, 24, 187-204, https://doi.org/ $10.1177 / 0972266119883165$.

Aswathy, P., and K. Kalpana, 2019: Good woman, bad woman: Social control and self-regulation in Kerala's artisanal fisheries. Women's Stud. Int. Forum, 74, 196-203, https://doi.org/ 10.1016/j.wsif.2019.04.006.

Attwood, D., 2018: Insight report on safety in the fishing industry: A global safety challenge. Lloyd's Register Foundation Rep., 47 pp., https://www.lrfoundation.org.uk/en/publications/insightreport-on-safety-in-the-fishing-industry/.
Balakrishnan Nair, T. M., and Coauthors, 2013: Performance of the Ocean State Forecast system at Indian National Centre for Ocean Information Services. Curr. Sci., 105, 175-181.

Bankoff, G., G. Frerks, and D. Hihorst, Eds., 2004: Mapping Vulnerability: Disasters, Development and People. Routledge, $256 \mathrm{pp}$.

Beck, U., 1992: Risk Society: Towards a New Modernity. Sage, 260 pp.

- 1996: The Reinvention of Politics: Rethinking Modernity in the Global Social Order. John Wiley and Sons, $206 \mathrm{pp}$.

Bhowmick, S. A., and Coauthors, 2019: An assessment of the performance of ISRO's SCATSAT-1 scatterometer. Curr. Sci., 117, 959-972.

Birkmann, J., and Coauthors, 2012: Framing vulnerability, risk and societal responses: The MOVE framework. Nat. Hazards, 67, 193-211, https://doi.org/10.1007/s11069-013-0558-5.

Blaikie, P., T. Cannon, I. Davies, and B. Wisner, 2004: At Risk: Natural Hazards, People's Vulnerability, and Disasters. Routledge, $471 \mathrm{pp}$.

Broad, K., A. S. P. Pfaff, and M. H. Glantz, 2002: Effective and equitable dissemination of seasonal-to-interannual climate forecasts: Policy implications from the Peruvian fishery during El Niño 1997-98. Climatic Change, 54, 415-438, https:// doi.org/10.1023/A:1016164706290.

Bulengela, G., P. Onyango, J. Brehm, P. A. Stæhr, and E. Sweke, 2020: "Bring fishermen at the center": The value of local knowledge for understanding fisheries resources and climate-related changes in Lake Tanganyika. Environ. Dev. Sustainability, 22, 5621-5649, https://doi.org/10.1007/ s10668-019-00443-z.

Campling, L., E. Havice, and P. McCall-Howard, 2012: The political economy and ecology of capture fisheries: Market dynamics, resource access and relations of exploitation and resistance. J. Agrar. Change, 12, 177-203, https://doi.org/ 10.1111/j.1471-0366.2011.00356.x.

Cannon, T., 2006: Vulnerability analysis, livelihoods and disasters. Risk 21: Coping with Risks Due to Natural Hazards in the 21st Century, W. J. Ammann, S. Dannenmann, and L. Vulliet, Eds., Taylor and Francis, 41-49.

Central Marine Fisheries Research Institute, 2010: Marine fisheries census 2010, Kerala. CMFRI Rep., 201 pp., http:// eprints.cmfri.org.in/9004/1/Ker_report_full.pdf.

—, 2015: CMFRI Annual Report 2014-15. CMFRI Rep., 353 pp, http://eprints.cmfri.org.in/10461/1/CMFRI\%20Annual\% 20Report\%202014-15.pdf.

_, 2020: CMFRI Annual Report 2018-19. CMFRI Rep., 320 pp., http://eprints.cmfri.org.in/13922/1/CMFRI\%20AR2019.pdf.

Cutter, S. L., L. Barnes, M. Berry, C. Burton, E. Evans, E. Tate, and J. Webb, 2008: A place-based model for understanding community resilience to natural disasters. Global Environ. Change, 18, 598-606, https://doi.org/ 10.1016/j.gloenvcha.2008.07.013.

Daipha, P., 2012: Weathering risk: Uncertainty, weather forecasting, and expertise. Sociol. Compass, 6, 15-25, https://doi.org/ 10.1111/j.1751-9020.2011.00437.x.

_ 2015a: From bricolage to collage: The making of decisions at a weather forecast office. Sociol. Forum, 30, 787-808, https://doi.org/10.1111/socf.12192.

_ 2015b: Masters of Uncertainty: Weather Forecasters and the Quest for Ground Truth. University of Chicago Press, 271 pp.

Deri, A., and J. Sundaresan, 2015: Diverse epistemic traditions in transformative climate change research and adaptation: Heritage and legacy. The Future of Heritage as Climates 
Change: Loss, Adaptation and Creativity, D. C. Harvey and J. Perry, Eds., Routledge, 78-94.

Devika, J., 2017: Surviving in contemporary Kerala: Reflections from recent research in a fisher Village. Dev. Change, 48, 364386, https://doi.org/10.1111/dech.12299.

Dietrich, G., and N. Nayak, 2002: Transition or transformation? A study of the mobilisation, organisation and the emergence of consciousness among the fishworkers of Kerala. Tamilnadu Theological Seminary Rep., 183 pp.

Douglas, M., and A. B. Wildavsky, 1982: Risk and Culture: An Essay on the Selection of Technical and Environmental Dangers. University of California Press, $221 \mathrm{pp}$.

Finnis, J., J. W. Shewmake, B. Neis, and D. Telford, 2019: Marine forecasting and fishing safety: Improving the fit between forecasts and harvester needs. J. Agromed., 24, 324-332, https://doi.org/10.1080/1059924X.2019.1639576.

Franke, R. W., and B. H. Chasin, 1994: Kerala: Development Through Radical Reform. Promila, 168 pp.

Ganga, A., 2019: Citizenship at the margins: Exploring participation as 'right to the city' in Vizhinjam, Kerala. Urbanisation, 4, 77-93, https://doi.org/10.1177/2455747119892347.

Geetanath, V., 2018: INCOIS traces swell waves to 9,000 km off Indian coast. Hindu, 18 April 2018, https://www.thehindu.com/news/cities/ Hyderabad/incois-traces-swell-waves-to-9000-km-off-indian-coast/ article23688000.ece.

Giddens, A., 1999: Risk and responsibility. Mod. Law Rev., 62, 110, https://doi.org/10.1111/1468-2230.00188.

Government of Kerala, 2015: Kerala marine fisheries statistics. Department of Fisheries Rep., 107 pp., https:// www.fisheries.kerala.gov.in/sites/default/files/2018-08/ marine_2015.pdf.

Hapke, H. M., and D. Ayyankeril, 2018: Gendered livelihoods in the global fish-food economy: A comparative study of three fisherfolk communities in Kerala, India. Marit. Stud., 17, 133143, https://doi.org/10.1007/s40152-018-0105-9.

Hewitt, K., 1997: Regions of Risk: A Geographical Introduction to Disasters. Longman, 389 pp.

_ 2013a: Environmental disasters in social context: Toward a preventive and precautionary approach. Nat. Hazards, 66, 3-14, https://doi.org/10.1007/s11069-012-0205-6.

_ 2013b: Disasters in 'development' contexts: Contradictions and options for a preventive approach. Jàmbá: J. Disaster Risk Stud., 5, https://doi.org/10.4102/jamba.v5i2.91.

Hoeppe, G., 2008: Knowing the sea in the "Time of Progress": Environmental change, parallel knowledges and the uses of metaphor in Kerala (south India). Culture and the Changing Environment: Uncertainty, Cognition and Risk Management in Cross-Cultural Perspective, M. J. Casimir, Ed., Berghahn Books, 301-324.

__, 2011: Extended vision: Finding fish like south Indian fishermen. Construire les Savoirs dans l'Action: Apprentissages et Enjeux Sociaux en Asie du Sud, M.-C. Mahias, Ed., Purusharta: Social Sciences in South Asia, Vol. 29, EHESS, 205-235, http://editions.ehess.fr/ouvrages/ouvrage/savoirset-savoir-faire-en-asie-du-sud/.

Hov, Ø., D. Terblanche, G. Carmichael, S. Jones, and P. M. Ruti, 2017: Five priorities for weather and climate research. Nature, 552, 168-170, https://doi.org/10.1038/d41586-017-08463-3.

IPCC, 2012: Managing the Risks of Extreme Events and Disasters to Advance Climate Change Adaptation. C. B. Field et al., Eds., Cambridge University Press, 582 pp.

- 2019: The Ocean and Cryosphere in a Changing Climate. H.-O. Pörtner et al., Eds., Cambridge University Press,
765 pp., https://www.ipcc.ch/site/assets/uploads/sites/3/2019/12/ SROCC_FullReport_FINAL.pdf.

Isaac, T. T. M., and R. W. Franke, 2000: Local Democracy and Development: People's Campaign for Decentralized Planning in Kerala. LeftWord Books, 359 pp.

Jaiswal, N., P. Kumar, and C. M. Kishtawal, 2019: SCATSAT-1 wind products for tropical cyclone monitoring, prediction and surface wind structure analysis. Curr. Sci., 117, 983-992, https://doi.org/10.18520/cs/v117/i6/983-992.

Jasanoff, S., 2010: A new climate for society. Theory Cult. Soc., 27, 233-253, https://doi.org/10.1177/0263276409361497.

Jolliffe, I. T., and D. B. Stephenson, Eds., 2003: Forecast Verification: A Practitioner's Guide in Atmospheric Science. John Wiley and Sons, $240 \mathrm{pp}$.

Kirchhoff, C. J., R. Esselman, and D. Brown, 2015: Boundary organizations to boundary chains: Prospects for advancing climate science application. Climate Risk Manage., 9, 20-29, https://doi.org/10.1016/j.crm.2015.04.001.

Krueger, R. A., and M. A. Casey, 2000: Focus Groups: A Practical Guide for Applied Researcher. 3rd ed. Sage, 215 pp.

Kurien, J., 1985: Technical assistance projects and socioeconomic change: Norwegian intervention in Kerala's Fisheries Development. Econ. Polit. Wkly., 20, A70-A88.

_- 1991: Ruining the commons and responses of the commoners: Coastal overfishing and fishermen's actions in Kerala State, India. United Nations Research Institute for Social Development Rep., 46 pp.

_ 1995: The Kerala model: Its central tendency and the outlier. Soc. Sci., 23, 70-90, https://doi.org/10.2307/3517892.

_ 1996: Diffusion as a process: The case of plywood boats in marine fishing. Rev. Dev. Change, 1/2, 219-234, https://doi.org/ 10.1177/0972266119960204.

_, 2004 : The socio-cultural aspects of fisheries: Implications for food and livelihood security-A case study of Kerala State, India. Understanding the cultures of fishing communities: A key to fisheries management and food security, J. R. McGoodwin, Ed., FAO Fisheries Tech. Paper 401, http:// www.fao.org/3/y1290e/y1290e0g.htm\#bm16.

- , and T. T. Achari, 1988: Fisheries development policies and the fishermen's struggle in Kerala. Soc. Action, 38, 15-36.

, and A. Paul, 2001: Social security nets for marine fisheries: The growth and changing composition of social security programmes in the fisheries sector of Kerala State. Centre for Development Studies Rep., 69 pp.

Latour, B., 2005: Reassembling the Social: An Introduction to Actor-Network-Theory. Oxford University Press, $301 \mathrm{pp}$.

Lemos, M. C., C. J. Kirchhoff, and V. Ramprasad, 2012: Narrowing the climate 593 information usability gap. Nat. Climate Change, 2, 789-794, https://doi.org/10.1038/nclimate1614.

— - - S. E. Kalafatis, D. Scavia, and R. B. Rood, 2014: Moving climate information off the shelf: Boundary chains and the role of RISAs as adaptive organizations. Wea. Climate Soc., 6, 273-285, https://doi.org/10.1175/WCAS-D13-00044.1.

Mathur, P. R., 1977: The Mappila Fisherfolk of Kerala: A Study in Inter-Relationship between Habitat, Technology, Economy, Society, and Culture. Anthropological Survey of India, $434 \mathrm{pp}$.

Meynen, W., 1989: Contradictions and constraints in fisheries development: Capital, artisanal workers, and fisheries development in Kerala. Institute for Social Studies Working Paper 51, 58 pp. 
Montz, B., 2009: Emerging issues and challenges: Natural hazards. J. Contemp. Water Res. Educ., 142, 42-45, https://doi.org/ 10.1111/j.1936-704X.2009.00051.x.

_ G. A. Tobin, and R. R. Hagelman III, 2017: Natural Hazards: Explanation and Integration. Guilford Press, 388 pp.

Murakami, H., G. A. Vecchi, and S. Underwood, 2017: Increasing frequency of extremely severe cyclonic storms over the Arabian Sea. Nat. Climate Change, 7, 885-889, https://doi.org/10.1038/ s41558-017-0008-6.

Murphy, A. H., 1993: What is a good forecast? An essay on the nature of goodness in weather forecasting. Wea. Forecasting, 8, 281-293, https://doi.org/10.1175/1520-0434(1993) $008<0281$ :WIAGFA $>2.0 . \mathrm{CO} ; 2$.

National Research Council, 1999: Making Climate Forecasts Matter. National Academies Press, 192 pp., https://doi.org/10.17226/6370.

- 2009: Informing Decisions in a Changing Climate. National Academies Press, 200 pp., https://doi.org/10.17226/12626.

_ 2010: Advancing the Science of Climate Change. National Academies Press, 526 pp., https://doi.org/10.17226/12782.

Oommen, M. A., Ed., 2007: A Decade of Decentralisation in Kerala: Experience and Lessons. Har-Anand, 252 pp.

Orlove, B., K. Broad, and A. Petty, 2004: Factors that influence the use of climate forecasts: Evidence from the 1997/98 El Niño Event in Peru. Bull. Amer. Meteor. Soc., 85, 1735-1743, https:// doi.org/10.1175/BAMS-85-11-1735.

Osella, F., and C. Osella, 2000: Social Mobility in Kerala: Modernity and Identity in Conflict. Pluto Press, 336 pp.

—-, M. Martin, K. Howland, P. Rowhani, and R. Stirrat, 2019: Forecasting with fishers to save lives at sea. University of Sussex and Institute of Development Studies SSRP Policy Brief 2, 4 pp., https://blogs.sussex.ac.uk/policy-engagement/ files/2019/02/2019-02-SSRP-Forecasting-for-Fishers-PolicyBriefing.pdf.

Ouso, B. C., 2014: A study of the phenomenon of social exclusion among the fisherfolk youth of Thiruvananthapuram and Ernakulam districts of Kerala in relation to their aggression, self-esteem and religious identity. Ph.D. Thesis, The University of Mumbai, $415 \mathrm{pp}$.

Pai, D. S., and M. N. Rajeevan, 2009: Summer monsoon onset over Kerala: New definition and prediction. J. Earth Syst. Sci., 118, 123-135, https://doi.org/10.1007/s12040-009-0020-y.

Panipilla, R., 2015: Eyes on their Fingertips: Some Aspects of the Arts, Science, Technology and Culture of the Fisherfolk of Thiruvananthapuram, India. International Collective in Support of Fishworkers, 96 pp.

Patt, A., and C. Gwata, 2002: Effective seasonal climate forecast applications: Examining constraints for subsistence farmers in Zimbabwe. Global Environ. Change, 12, 185-195, https:// doi.org/10.1016/S0959-3780(02)00013-4.

Pattnaik, S., 2019: Weather forecasting in India: Recent developments. Mausam, 70, 453-464.

Pelling, M., 2003: The Vulnerability of Cities: Natural Disasters and Social Resilience. Earthscan Publications, $224 \mathrm{pp}$.

- 2010: Adaptation to Climate Change: From Resilience to Transformation. Routledge, $212 \mathrm{pp}$.

Power, N. G., 2008: Occupational risks, safety and masculinity: Newfoundland Fish harvesters' experiences and understandings of fishery risks. Health Risk Soc., 10, 565-583, https:// doi.org/10.1080/13698570802167405.

Punathil, S., 2018: Interrogating Communalism: Violence, Citizenship and Minorities in South India. Taylor and Francis, 176 pp.

Ram, K., 1991: Mukkuvar Women: Gender, Hegemony and Capitalist Transformation in a South Indian Fishing Community. Zed Books, 266 pp.
Ramachandran, V. K., 1997: On Kerala's development achievements. Indian Development: Selected Regional Perspectives, A. Sen and J. Dreze, Eds., Oxford University Press, https:// doi.org/10.1093/acprof:oso/9780198292043.001.0001.

Rasmussen, L. V., and O. Mertz, 2014: Weather, climate, and resource information should meet the needs of Sahelian pastoralists. Wea. Climate Soc., 6, 482-494, https://doi.org/ 10.1175/WCAS-D-14-00010.1.

Rijiju, K., 2018: Minister of State in the Ministry of Home Affairs, Lok Sabha unstarred question No. 4055 to be answered on 20 March 2018. Government of India Ministry of Home Affairs Doc., 5 pp., https://www.mha.gov.in/MHA1/Par2017/ pdfs/par2018-pdfs/ls-20032018/LSQ.4055.pdf.

Roncoli, C., and Coauthors, 2009: From accessing to assessing forecasts: An end-to-end study of participatory climate forecast dissemination in Burkina Faso (West Africa). Climatic Change, 92, 433-460, https://doi.org/10.1007/s10584-008-9445-6.

Roshan, M., 2018: Cyclone Ockhi: Disaster Risk Management and Sea Safety in the Indian Marine Fisheries Sector. Samudra Monogr., International Collective in Support of Fishworkers, 73 pp., https://www.icsf.net/images/monographs/pdf/english/issue_ 165/165_Ockhi_Study_Manas_2018.pdf.

Saldanha, M. C. W., R. J. M. de Carvalho, R. Arcuri, A. G. Amorim, M. C. R. Vidal, and P. V. R. de Carvalho, 2020: Understanding and improving safety in artisanal fishing: A safety-II approach in raft fishing. Saf. Sci., 122, e104522, https://doi.org/10.1016/ j.ssci.2019.104522.

Samimian-Darash, L., and P. Rabinow, Eds., 2015: Modes of Uncertainty: Anthropological Cases. University of Chicago Press, $250 \mathrm{pp}$.

Santha, S. D., P. Gahana, and V. S. Aswin, 2014: Local knowledge, early warning and coastal hazards: Participatory inquiry among fishworkers in Kerala, India. Action Res., 12, 273-292, https://doi.org/10.1177/1476750314532504.

Sathiadhas, R., 2006: Socio economic scenario of marine fisheries in Kerala-Status and scope for improvement. Sasthrapadham National Seminar, Bombay, India, Sasthrapadham Institute of Social Sciences, 149-160, http://eprints.cmfri.org.in/5649/1/Socio_ Economic_Scenario_of_Marine._Fisheries_in_Kerala_-_Status_ and_Scope_for_Improvement..pdf.

Seethi, K. M., 1995: Vizhinjam riots: Fishing for higher stakes. Towards Secular India, 1 (3), 1-6.

Shyam, S. S., V. Kripa, P. U. Zacharia, N. Shridhar, and T. V. Ambrose, 2014: Climate change awareness, preparedness, adaptation and mitigation strategies: Fisherfolks perception in coastal Kerala. J. Aquat. Biol. Fish., 2, 670-681, http:// keralamarinelife.in/Journals/Vol2-2/104.pdf.

Slawson, N., 2017: Radio Monsoon aims to ensure safety reigns among fishermen in south India. Guardian, 24 April 2017, https:/www.theguardian.com/global-development/2017/apr/ 24/radio-monsoon-safety-fishermen-south-india-kerala.

South Indian Federation of Fishermen Societies, 2017: Sea safety incidents on the lower south west coast of India, Thiruvananthapuram. SIFFS Doc., 40 pp.

State Planning Board, 2017: Economic Review 2017. Government of Kerala, https://spb.kerala.gov.in/economic-review/ER2017/ web_e/index.php.

Subramanian, A., 2009: Shorelines: Space and Rights in South India. Stanford University Press, 320 pp.

Subrahmanian, K. K., and S. Prasad, 2008: Rising inequality with high growth: Isn't this trend worrisome? Analysis of Kerala experience. Centre for Development Studies Working Paper 401, 44 pp., https:/opendocs.ids.ac.uk/opendocs/handle/20.500.12413/3106. 
Sundar, A., 2012: Thinking beyond secularism: The Catholic Church and political practice in rural south India. South Asia Multidiscip. Acad. J., 2012, 3368, https://doi.org/10.4000/ samaj.3368.

_ 2019: Skills for work and the work of skills: Community, labour and technological change in India's artisanal fisheries. J. South Asian Dev., 13, 272-292, https://doi.org/10.1177/ 0973174118804449.

Szerszynski, B., 1999: Risk and trust: The performative dimension. Environ. Values, 8, 239-252, https://doi.org/10.3197/ 096327199129341815.

__ S. Lash, and B. Wynne, 1996: Introduction: Ecology, realism and the social sciences. Risk, Environment and Modernity, S. Lash, B. Szerszynski, and B. Wynne, Eds., Sage, 1-26.

Unnikrishnan, S., 2020: Rule violations and fatalities haunt Muthalapozhi harbour. New Indian Express, 19 September 2020, https://www.newindianexpress.com/cities/thiruvananthapuram/ 2020/sep/19/rule-violations-andfatalities-hauntmuthalapozhiharbour-2198752.html.
Vogel, C., and K. O'Brien, 2006: Who can eat information? Examining the effectiveness of seasonal climate forecasts and regional climate-risk management strategies. Climate Res., 33, 111-122, https://doi.org/10.3354/cr033111.

, A. Steynor, and A. Manyuchi, 2019: Climate services in Africa: Re-imagining an inclusive, robust and sustainable service. Climate Serv., 15, 100107, https://doi.org/10.1016/ j.cliser.2019.100107.

Wilks, D. S., 2005: Statistical Methods in the Atmospheric Sciences. Academic Press, 627 pp.

WMO, 1998: Guide to wave analysis and forecasting. 2nd ed. WMO Tech. Doc. WMO/TD-702, 159 pp., https://doi.org/ 10.25607/OBP-1523.

- 2000: Guidelines on performance assessment of public weather services. WMO Tech. Doc. WMO/TD-1023, 67 pp., https://library.wmo.int/doc_num.php?explnum_id=5301.

, 2018: Manual on Marine Meteorological Services Volume I-Global Aspects: Annex VI to the WMO Technical Regulations. WMO Tech. Doc. WMO/TD-558, 73 pp. 